\title{
Tachistoscopic thresholds following three kinds of paired-associate learning '
}

WILMA A, WINMICK ANO MICHAEL S. LEVINE

QUEENS COLLEGE OF THE CITY UNIVERSITY OF NEW YORK

Three experiments employed various methods of PA learning; after learning, tachistoscopic thresholds were measured for stimulus (S) words, response (R) words, and control (C) words. Tachistoscopic measurements found thresholds for $R$ words to be significantly lower than thresholds for $S$ words following only two of the methods: standard anticipation with pronunciation of $R$ words only and the discriminative situation, which also required pronunciation of $R$ words only.

An earlier word recognition study (Winnick \& Nachbar, 1967) found tachistoscopic thresholds obtained after paired-associate (PA) learning to be significantly lower for the response (R) words than for the stimulus (S) words, while control (C) words had the highest thresholds.

In the present study, three experiments used variations of the basic methods of PA learning, followed by tachistoscopic threshold measurement for $S, R$, and $\mathrm{C}$ words. The purpose was to determine whether differences between $S$ and $R$ words would be stable as learning methods varied.

\section{Experimental Design}

The three experiments reported were of "mixed" design; in each experiment the variable of word type (S, R, C) was a "within-Ss" effect. In Experiments 1 and 2, there were two "between-Ss" effects; one consisted of three replications, carried out to counterbalance words across word types, and the other was method of PA learning. Experiment 3, which used discriminative PA learning, had only replications as a "between-Ss" effect.

\section{Subjects}

Introductory psychology students served as Ss in all of the experiments. There were $45 \mathrm{Ss}$ in Experiment 1 and 45 Ss in Experiment 2, with 15 learning by each of the three methods used in each experiment; Experiment 3 used $30 \mathrm{Ss}, 10$ in each replication.

Apparafus and materials

The words used, chosen from the Thorndike-Lorge (1944) counts, consisted of 30 low (1-2 per million) frequency English nouns of seven or eight letters, arranged into three lists of 10 words each; in the three replications employed, the three lists were counterbalanced across word types.

Word pairs were presented for all PA learning in a Lafayette memory drum with long-arm attachment (model 303B). For the measurement of tachistoscopic thresholds, words typed in capital letters and centered on the cards were presented in a Gerbrands tachistoscope.

\section{Procedure}

Each experiment consisted of PA learning followed by tachistoscopic threshold measurement. For PA learning, five different sequences were shown in the memory drum to avoid serial learning. The rate of exposure was generally $4 \mathrm{sec}$ per pair (with some variation as dictated by particular methods), and a 4-sec intertrial interval was used. Learning was carried out to the criterion of one errorless trial. Following PA learning, threshold measurements were obtained for 30 words; of these, 10 were $S$ words, 10 were $R$ words, and 10 had not been seen before (C).

In the three PA learning methods of Experiment 1, $S$ was required to pronounce $R$ words while $E$ recorded them. Group 1A learned by the standard anticipation method, with standard anticipation instructions modified to emphasize that $\mathbf{S}$ must pronounce the $\mathbf{R}$ but not the $S$ word. Group 1B learned by essentially the same method as did Group 1A, except that $S$ was instructed to pronounce the $S$ item and then to anticipate the $R$ word by attempting to pronounce it. Ss in Group $1 \mathrm{C}$ did not pronounce the $S$ and $R$ pairs exposed for the 4-sec interval; they were required to attempt free recall after each trial, by pronouncing both $S$ and $R$ items.

For the three groups in Experiment 2, there was no overt verbalization of either $S$ or $R$ words during learning or recall trials, and both were exposed simultaneously for $4 \mathrm{sec}$. Ss in Group $2 \mathrm{~A}$ were instructed to write down as many of the $S-R$ pairs as possible after each trial. Group 2B was given, after each trial, a list of the $10 \mathrm{~S}$ words and asked to write down the $R$ word belonging with each. The $\mathrm{Ss}$ in Group $2 \mathrm{C}$ were given a list of $S$ words and instructed to match correct $R$ words from a list of 30 nouns of the same frequency and length as the $R$ words.

Experiment 3 used the method of discriminative PA learning, which requires $S$ to choose and to learn the correct $R$ word from two simultaneously exposed with each S word; standard discriminative PA instructions were used. Total exposure for the $S$ item and correct $R$ item was 4 sec.

Tachistoscopic threshold measurements followed practice with common words. For threshold measurement, $S, R$, and $C$ words were exposed in random sequence, using the ascending method of limits, starting at .01 sec and proceeding by $.005 \mathrm{sec}$ increments until correct identification was made. In Experiment 3, the incorrect response (Rx) items were substituted for C words. 


\section{Results and Discussion}

Paired-associate leaming. Table 1 summarizes the mean trials required to reach criterion by the different PA learning methods of the three experiments. Although a comparison of these learning methods might be of interest, this was not the main purpose of the present study.

Tachistoscopic thresholds. Table 2 summarizes the tachistoscopic threshold data obtained for the S, R, and $\mathrm{C}$ ( $\mathrm{Rx}$ for Experiment 3) words following the various learning methods in the three experiments. The thresholds shown there reveal differences in the predicted direction between $S$ and $R$ words only in Group 1A and in Experiment 3.

Three separate analyses of variance were carried out on the data of the three experiments. For Experiment 1 , this analysis found significance in the word type $(F=75.3, d f=2 / 72, p<.005)$. Follow-up " $t$ " tests for means of related samples found $S-R$ differences to be significant only for Group 1A $(t=2.64, d f=14, p<$ $.05)$; this group replicated the method used by Winnick \& Nachbar (1967). The pronouncing of the $R$ words in Method 1A caused lower thresholds for $R$ words than for $S$ words, while no such differences were found in the other two methods. Independent " $t$ " tests also compared means for the $S$ words and means for the $R$ words of the three different methods. Only two values showed significance; $R$ words in Group $1 \mathrm{~A}$ were significantly lower than in Group 1B $(t=2.95, d f=28, p<.05) . R$ words in Group $1 \mathrm{~A}$ were also significantly lower than in Group $1 C(t=2.05, d f=28, p<.05)$. The analysis of variance of the data of Experiment 1 also found the interaction between word type and replications to be significant $(\mathrm{F}=2.62, \mathrm{df}=4 / 72, \mathrm{p}<.05)$; this significant interaction stemmed from excessively high thresholds for the $\mathrm{C}$ words in two of the replications.

The analysis of variance of the data of Experiment 2 showed significance only in the main effect of word type $(F=9.17$, df $=2 / 54, p<.001)$. Multiple " $t$ " tests for means from independent and related samples computed for Experiment 1 showed no significant differences between $S$ and $R$ words in the same methods and

Table 1. Mean trials to criterion and standard deviation for the leaming methods used in the three experiments

\begin{tabular}{llrr} 
Experiment & Group & Mean & SD \\
\hline 1: pronounce R & A: standard anticipation & 12.06 & 4.6 \\
& B: pronounce S, anticipate R & 15.31 & 5.8 \\
& C: free recall, pronouncing S and R & 7.67 & 2.3 \\
2: no overt & A: written free recall & 8.12 & 2.0 \\
verbalization & B: written recall of R items & 5.43 & 2.6 \\
& C: written recognition of R items & 4.67 & 1.6 \\
3: Discriminative PA learning & 2.43 & 1.3 \\
\hline
\end{tabular}

Table 2. Mean tachistoscopic thresholds (in msec) for all word types in the three experiments

\begin{tabular}{|c|c|c|c|c|c|}
\hline \multirow[b]{2}{*}{ Exp. } & \multirow[b]{2}{*}{ Group } & \multicolumn{3}{|c|}{ Type of Word } & \multirow[b]{2}{*}{ Control } \\
\hline & & & Stimulus & Response & \\
\hline \multirow[t]{6}{*}{1} & $A$ & Mean & 22.8 & 21.0 & 47.3 \\
\hline & & SD & 6.4 & 8.4 & 22.5 \\
\hline & B & Mean & 27.5 & 29.7 & 73.6 \\
\hline & & SD & 5.9 & 9.8 & 38.3 \\
\hline & $\mathrm{C}$ & Mean & 25.5 & 26.9 & 63.9 \\
\hline & & SD & 7.1 & 10.2 & 45.7 \\
\hline \multirow[t]{7}{*}{2} & $A$ & Mean & 24.9 & 24.8 & 52.6 \\
\hline & & SD & 2.0 & 2.6 & 54.9 \\
\hline & B & Mean & 25.6 & 27.5 & 50.3 \\
\hline & & SD & 5.9 & 9.8 & 34.6 \\
\hline & $C$ & Mean & 23.8 & 24.3 & 40.4 \\
\hline & & SD & 7.1 & 9.2 & 25.4 \\
\hline & & Stim & iulus & Correct Response & Incorrect Response \\
\hline \multirow[t]{2}{*}{3} & & Mean & 27.3 & 25.2 & 31.2 \\
\hline & & SD & 9.9 & 7.8 & 13.7 \\
\hline
\end{tabular}

$\mathbf{S}$ and $\mathbf{R}$ words across different methods. Therefore, these three PA learning methods did not produce differential tachistoscopic thresholds for $\mathrm{S}$ and $\mathrm{R}$ words.

For the data of Experiment 3, the analysis of variance showed only the main effect of word type to be significant ( $F=9.17, d f=2 / 54, p<.001$ ). Follow-up " $t$ " tests for the means of related samples found significance in all differences among $S, R$, and $R_{x}$ words. $S$ words had significantly higher thresholds than did $R$ words $(t=2.96, d f=29, p<.01)$. The $R$ words had significantly lower thresholds than $R_{x}$ words ( $t=3.39$, $d f=29, p<.01)$. And $S$ words were found to have significantly lower threshold than $R_{x}$ words $(t=2.50, d f=$ 29, $p<.05$ ).

It can be concluded, from the results of these experiments, that a lowered threshold for $\mathbf{R}$ words compared to $S$ words will result only when prior PA learning has involved overt pronunciation of $R$ words only. This finding suggests that the effect results from the response learning necessitated by either the standard anticipation method (as in Group 1A) or the discriminative method (as in Experiment 3) of paired-associate learning.

\section{References}

Thomdike, E. L., \& Lorge, I. The teacher's word book of 30,000 words. New York: Columbia University Press, 1944.

Winnick, Wilma A., \& Nachbar, S. Tachistoscopic thresholds following paired-associate learning. J. verbal Learn. verbal Behav., $1967,6,94-99$.

\section{Note}

1. Supported by a grant to the first author from the National Institutes of Health (MH 11580-01) entitled "Studies of verbal learning and word recognition". Participation of the second author was made possible by a National Institutes of Health undergraduate research training grant (No, 2T2-7311-05). 